\section{Characteristics of Sugar Content in Different Sections and Harvest Maturity of Bamboo Shoots}

\author{
Manasikan Thammawong, Daisuke Nei, Poritosh Roy, \\ Nobutaka Nakamura, and Takeo Shiina ${ }^{1}$ \\ Food Engineering Division, National Food Research Institute, National \\ Agriculture and Food Research Organization, 2-1-12 Kannondai, Tsukuba, \\ Ibaraki, 305-8642, Japan
}

\author{
Yuuichi Inoue \\ Yamaguchi Prefectural Forestry Guidance Institute, 1768-1 Miyanokami, \\ Yamaguchi city, Yamaguchi, 753-0001, Japan
}

\section{Hidenobu Hamachi \\ Fukuoka Forest Research and Extension Center, 1438-2 Toyoda, Yamamotomachi, Kurume, Fukuoka, 839-0827, Japan}

\author{
Shigeyuki Nonaka \\ Fukuoka Special Forest Product Promotion Association, 3-10-25 Tenjin, \\ Chuouku, Fukuoka, 810-0001, Japan
}

Additional index words. emerged bamboo shoot, HPLC analysis, storage, temperature, underground bamboo shoot

\begin{abstract}
Bamboo shoots (Phyllostachys pubescens Mazel) harvested from two cultivation areas were used to investigate the amount of accumulated sugars (sucrose, glucose, and fructose) in four sections along the length of a bamboo shoot. Bamboo shoots harvested from above ground (emerged bamboo shoot) and underground of the same cultivation area were also used to study the changes in sugar content during storage at both 5 and 25 ${ }^{\circ} \mathrm{C}$. The amounts of sucrose, glucose, fructose, and total sugar of underground bamboo shoots were higher than those of emerged shoots. Sucrose content in the apical section was significantly higher than that in other sections. Meanwhile, higher amounts of glucose, fructose, and total sugar (the sum of sucrose, glucose, and fructose) were observed in the basal section. Changes in sugar content were also observed during storage. The fresh, unpeeled bamboo shoots have particular cellular chemical properties and respond differently to storage duration and condition depending on harvest maturity.
\end{abstract}

Bamboo shoots are immature, expanding portions of new culms that develop from the rhizome of bamboo plants (Liese, 1998). Young bamboo culms with compressed internodes and including a culm neck are generally harvested for edible shoots. The edible part of the shoots consists of meristematic tissue with regions of rapid cell division and differentiation, which is enveloped in protective leaf sheaths (Kleinhenz et al., 2000). Bamboo shoot is a well-known ingredient used in numerous types of Japanese, Chinese, and other Asian cuisine and is important for the human diet. Furthermore, bamboo shoots are commonly available as canned food, although fresh bamboo shoots

\footnotetext{
Received for publication 10 Apr. 2009. Accepted for publication 6 Oct. 2009.

We thank "Research project for utilizing advanced technologies in agriculture, forestry and fisheries" (funded by MAFF) for financial support.

${ }^{1}$ To whom reprint requests should be addressed; e-mailshiina@affrc.go.jp.
}

are far superior in taste and texture. According to importance of bamboo shoots in food material, previous studies on the consumption and nutritional benefits of bamboo shoots have focused on dietary fiber, lipid, fatty acid, protein, and amino acid contents. Postharvest attributes, including water loss, discoloration, and microbial decay, have also been studied (Fuchigami, 1990; Kleinhenz et al., 2000; Kozukue and Kozukue, 1981; Nirmala et al., 2007).

Sweetness is one of the most predominant factors affecting eating quality of fruits and vegetables. Lu and Xu (2004) have suggested that total sugar content and sugar in the basal, middle, and apical sections of fresh-cut bamboo shoots initially decreased and then changed variably thereafter in different sections of the shoots during storage at $4{ }^{\circ} \mathrm{C}$ for 16 d. Kozukue et al. (1983) also found that fructose, glucose, and sucrose were the major sugar constituents in all bamboo sections. The content of both fructose and glucose in the basal section was twice as high as in the apical section. These studies showed a differ- ence in sugar content in different sections along the length of a bamboo shoot. However, comprehensive and accurate data on the sugar profiles in various bamboo shoots (four different sections along the length, different harvest maturity, and different cultivation areas) are not available.

Maturity stage at harvest is another determinant influencing compositions, eating quality, and storage life of fresh produce. Although there have been many studies on determining suitable maturity indices, only limited studies have dealt with the relationship between maturity and eating quality of fruit and vegetables (Kader, 1996). Temperature also plays a major role in maintaining quality after harvest. Lowering temperature reduces respiration as well as other metabolic processes and therefore delays quality deterioration. On the other hand, high temperature accelerates many chemical reactions, causing senescence, softening, loss of nutrition, and other cellular components (Bron et al., 2005; Kattan and Pharr, 1971; Platenius, 1942; Saltveit, 2004). In unpeeled fresh bamboo shoots, however, the effects of harvest maturity and temperature on the changes in eating quality during storage have not been well analyzed.

Therefore, in this study, the individual sugar contents of bamboo shoots harvested from different maturities (emerged and underground position) were determined. This work also investigates the effects of storage conditions on the changing characteristics of cellular sugar components in bamboo shoots, which, in turn, influence eating quality.

\section{Materials and Methods}

Plant materials and treatments. The emerged and underground bamboo shoots (Phyllostachys pubescens Mazel) were obtained from the Kurume (Kamitsu Town, Kurume City; "A") and Ohma (Ohma Area, Kitakyushu City; "B") cultivation areas (Fukuoka prefecture, Japan) in the commercial harvest on 21 Apr. 2008 (Fig. 1A). They were immediately transported to the laboratory by a courier system with coolant $\left(5^{\circ} \mathrm{C}\right.$, $\approx 18 \mathrm{~h}$ ). On arrival (indicated as Day 0), 36 shoots were selected for experimentation based on uniformity of shape and size. Then, the samples were cleaned by laboratory paper towel. The averages of length (from base to top) and basal perimeter of the unpeeled bamboo shoot samples were $25.1 \pm 5.8 \mathrm{~cm}$ and $24.7 \pm 6.6 \mathrm{~cm}$, respectively. The significant differences of these parameters were not observed among harvesting areas. In this study, one bamboo shoot (four sections as shown in Fig. 1B) represented one replicate. Three replicate samples were used throughout the study. The selected 12 bamboo shoots from both areas "A" (emerged and underground) and "B" (emerged and underground) were peeled and $\approx 1 \mathrm{~cm}$ height from the detached surface was sliced off. Each individual shoot was then cut into four sections from apical to basal along the length of the shoots (Fig. 1B). The four parts of 
peeled bamboo shoots from apical to basal were indicated as the first, second, third, and fourth sections. The average length of each section of the peeled sample was 2 to 3 $\mathrm{cm}$. Each section of bamboo shoot (from samples from both areas) was cut into small pieces, weighed, and immediately frozen in liquid nitrogen. The frozen samples were then kept at $-40{ }^{\circ} \mathrm{C}$ until analysis of sugar content. To investigate the changes in sugar content at different storage temperatures and to allow gas exchange and prevent water loss, the remaining unpeeled 24 bamboo shoots from area "B" (emerged and underground) were separated into eight groups and kept in closed and unsealed polyethylene bags at 5 or $25^{\circ} \mathrm{C}$ for analysis at Days 3 and 6. For two temperature treatments used in this study, $5^{\circ} \mathrm{C}$ is the common cold storage temperature for fruits and vegetables and $25{ }^{\circ} \mathrm{C}$ is the highest ambient temperature during the harvesting period of bamboo shoots.

Preparation of samples for highperformance liquid chromatography analysis. The sugar determination method used in this study was derived from Pharr and Sox (1984) and Wang et al. (1999). Briefly, $5 \mathrm{~g}$ of the frozen bamboo sample was directly immersed and homogenized with 20 to $25 \mathrm{~mL}$ of $80 \%(\mathrm{v} / \mathrm{v})$ ethanol twice (each for $3 \mathrm{~min}$ ) at 15,000 rpm (Physcotron homogenizer, Model NS-51, Chiba, Japan). The homogenate was centrifuged at $2525 \times \mathrm{g}$ for 10 min (biofuge primo; SORVALL ${ }^{\circledR}$, Osaka, Japan) to yield ethanol-soluble and ethanolinsoluble fractions. The ethanol-soluble fraction was pooled and evaporated to dryness by incubation at $70{ }^{\circ} \mathrm{C}$ for $3 \mathrm{~h}$ and then redissolved in $2 \mathrm{~mL}$ of distilled water. These procedures yielded a concentrated suspension to accurately analyze individual sugar content. The soluble fraction was recentrifuged at $16,060 \times \mathrm{g}$ for $3 \mathrm{~min}$ (biofuge pico; SORVALL ${ }^{\circledR}$ ) to give a clear solution and then filtered.

Preparation of standards for highperformance liquid chromatography analysis. Standard solutions $\left(5 \mathrm{mg} \cdot \mathrm{mL}^{-1}\right.$ and 10 $\mathrm{mg} \cdot \mathrm{mL}^{-1}$ ) of sucrose, glucose, and fructose (Wako Pure Chemical Industries, Ltd., Osaka, Japan) were prepared by dissolving the mixed standards in distilled water.

High-performance liquid chromatography analysis. The mixed standard or sample (20 $\mu \mathrm{L})$ was measured with a high-performance liquid chromatograph (Shimadzu, Kyoto, Japan). Degassed, distilled, deionized water at $0.6 \mathrm{~mL} \cdot \mathrm{min}^{-1}$ at $60{ }^{\circ} \mathrm{C}$ was used as the mobile phase. A refractive index detector (RID-10A; Shimadzu) was used to quantify sugar content after separation with a Shimpack SCR-101N column (Shimadzu).

Data analysis. Analysis of variance with a completely randomized design using bamboo shoot sections or days of storage as a factor was performed using SPSS (SPSS, Chicago, IL). Tukey's multiple-range test was used to test for a significant difference at the $95 \%$ confidence level of each variable.

\section{Results}

Sugar content among sections along the length of bamboo shoot harvested from different harvesting maturity and cultivation areas at Day 0. The total sugar content for each section of underground samples is approximately twice that of the correspond- ing section of emerged samples (Fig. 2). For bamboo shoots harvested from the same area, the statistical $t$ test analysis of each individual section also showed the significant difference of total sugar content between emerged and underground bamboo shoots (data not shown). The contents of sucrose, glucose, and fructose in the underground bamboo

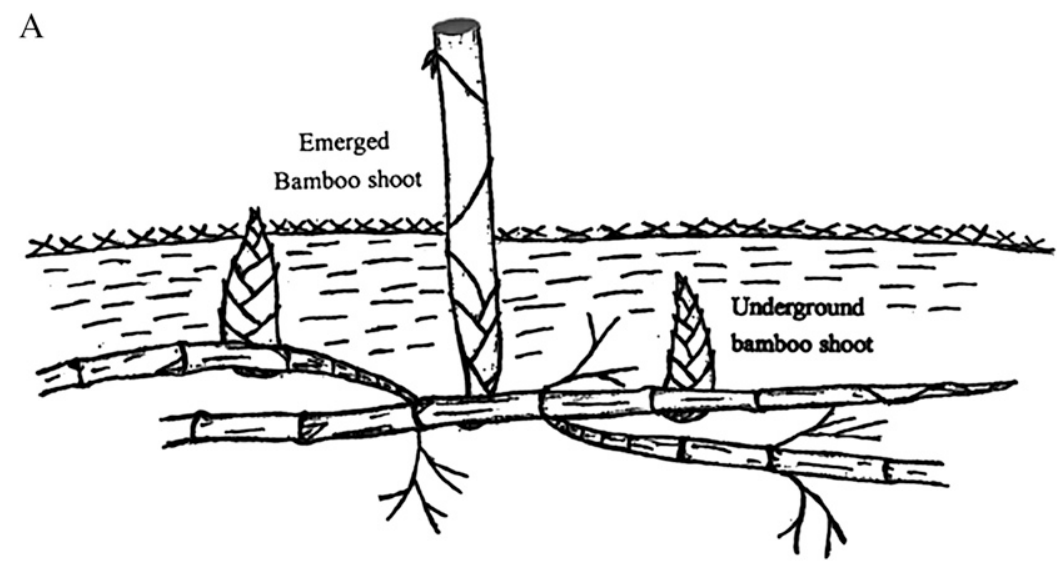

B

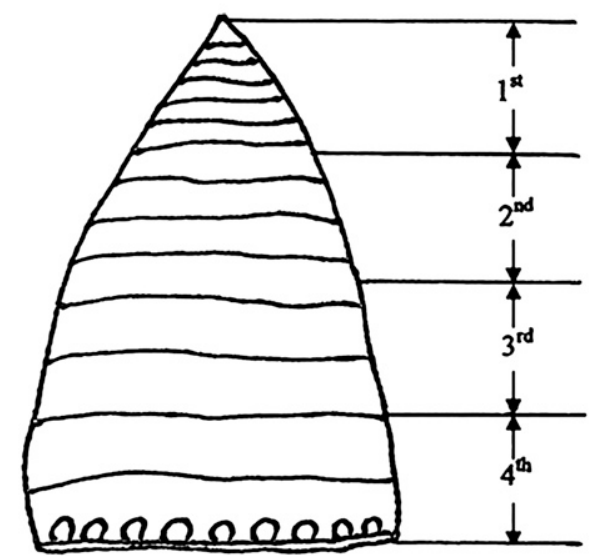

Fig. 1. (A) A schematic diagram of emerged and underground bamboo shoots at harvest. (B) Sections of peeled bamboo shoots for chemical analysis.

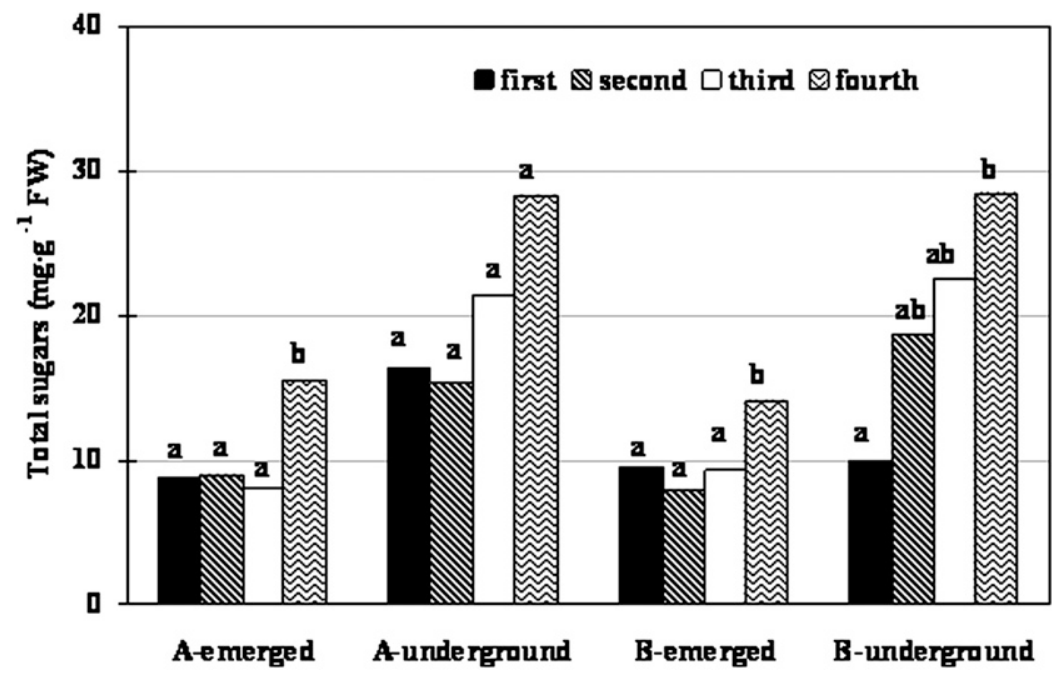

Fig. 2. Total sugar contents in different sections along the length of a bamboo shoot harvested at different maturity and cultivation areas; Kurume area (A-emerged and A-underground), Ohma area (Bemerged and B-underground) at Day 0. Each value is the mean of three replicates. Mean values with the same letter are not significantly different at the $5 \%$ level by Tukey's multiple range test. 
shoots were higher than those of emerged bamboo shoots except for sucrose content in the first section of Ohma-underground (Fig. $3)$. Additionally, in all bamboo shoots, there was no difference in the accumulation patterns of each individual sugar. For each harvesting maturity (emerged or underground), sugar contents differed in different sections along the length of the bamboo shoot from the apical to the basal section. Higher glucose, fructose, and total sugar contents were observed in the fourth section. Moreover, the sucrose content of the first section in all bamboo shoots seemed to be higher than the other three sections, although a statistically significant difference in sucrose content among sections was only observed in the emerged bamboo shoot from the 'Ohma' cultivation area (Fig. 3C).

Difference in sugar content among sections along the length of bamboo shoot during storage. A difference in sugar content among storage conditions was observed between Days 3 and 6. For all treatments of the emerged and underground bamboo shoots during storage, the highest sucrose content was observed in the first section of all bamboo shoots, whereas the greatest contents of glucose and fructose were observed in the fourth section (Figs. 4 and 5). Because these individual sugar content patterns were predominant in all treatments, the sucrose content obtained from the first section as well as the glucose and fructose contents obtained from the fourth section were therefore used to represent the changing characteristics of sugar content during storage between emerged and underground bamboo shoots.
For the emerged bamboo shoots stored at $5{ }^{\circ} \mathrm{C}$, the contents of sucrose, glucose, and fructose increased at Day 3 and had declined slightly at Day 6. Sugar contents in the bamboo shoots stored at $25{ }^{\circ} \mathrm{C}$ had also increased at Day 3 but dropped significantly at Day 6 (Fig. 6). In addition, this similar changing tendency was found in the total sugar content. The difference in total sugar among sections was not significant; however, the total sugar content at both storage temperatures $\left(5\right.$ and $\left.25^{\circ} \mathrm{C}\right)$ seemed to increase at Day 3 and then drop at Day 6 of storage.

For the bamboo shoots harvested from the underground position, the fourth section of the shoots revealed the highest total sugar content at Day 0. Total sugar content then decreased at Day 3 and slightly increased at Day 6 (Fig. 5D). The sucrose content at both storage temperatures increased at Day 3 and then dropped slightly at Day 6, which is similar to that of emerged bamboo shoots. However, for the underground bamboo shoots, the glucose and fructose contents at both Day 3 and Day 6 of storage were lower than that at Day 0 (Fig. 6).

\section{Discussion}

Diver (2001) mentioned that once the bamboo shoots emerge from the ground, they quickly become tough and bitter. The higher eating quality of bamboo shoots was also reported when the shoots were gathered at the early growth stage (Liese, 1987). In Japan, the bamboo shoots are generally harvested when the apical part is just emerged from the ground. Emerged bamboo shoots are com- mercially available in the markets and popular among Japanese consumers. However, our results showed that the contents of sugar in the emerged bamboo shoots were lower than those in underground bamboo shoots harvested from the same area (Fig. 2). It suggests that the bamboo shoots harvested from the deeper position beneath the ground surface is sweeter than the emerged bamboo shoots. This finding helps us to better understand how bamboo shoot quality is affected by harvest maturity. The particular characteristic of cellular sugar content observed in this study possibly could be used as one of the aspects to indicate the maturity of bamboo shoots. Moreover, because good eating quality of bamboo shoots attracts consumers' preference, the improvement in growing techniques to yield high-quality underground bamboo shoots is greatly recommended and should be taken into consideration for further practice and research. Additionally, for fast-growth bamboo shoot, the rate of daily expansion of the emerged bamboo shoots was vigorous (a constant daily growth rate of $\approx 7 \mathrm{~cm}$ was maintained until the final height of $\approx 220 \mathrm{~cm}$ ) simultaneously to high respiration rate (Luo et al., 2007; Magel et al., 2005). Although sugars are highly accumulated in underground bamboo shoots, the emerged bamboo shoots may greatly use their accumulated sugar to support active shoot growth, elongation, and respiratory processes.

In previous reports, Kozukue et al. (1983) suggested that fructose, glucose, and sucrose were the major sugar constituents in all bamboo shoot sections. The contents of both
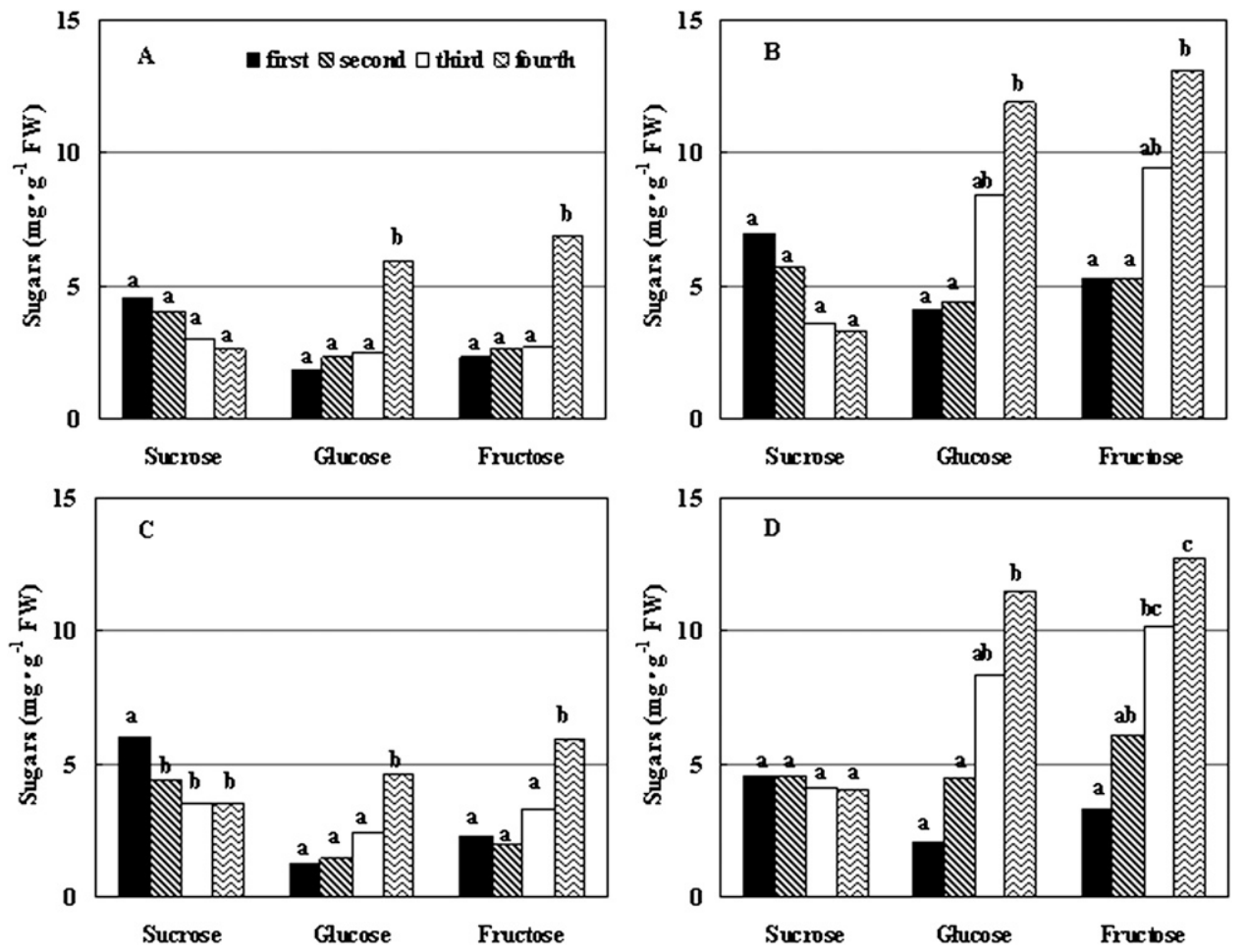

Fig. 3. Individual sugar contents in different sections along the length of a bamboo shoot harvested at different maturity and cultivation areas; Kurume-emerged (A), Kurume-underground (B), Ohma-emerged (C), and Ohma-underground (D) at Day 0. Each value is the mean of three replicates. Mean values with the same letter are not significantly different at the $5 \%$ level by Tukey's multiple range test. 

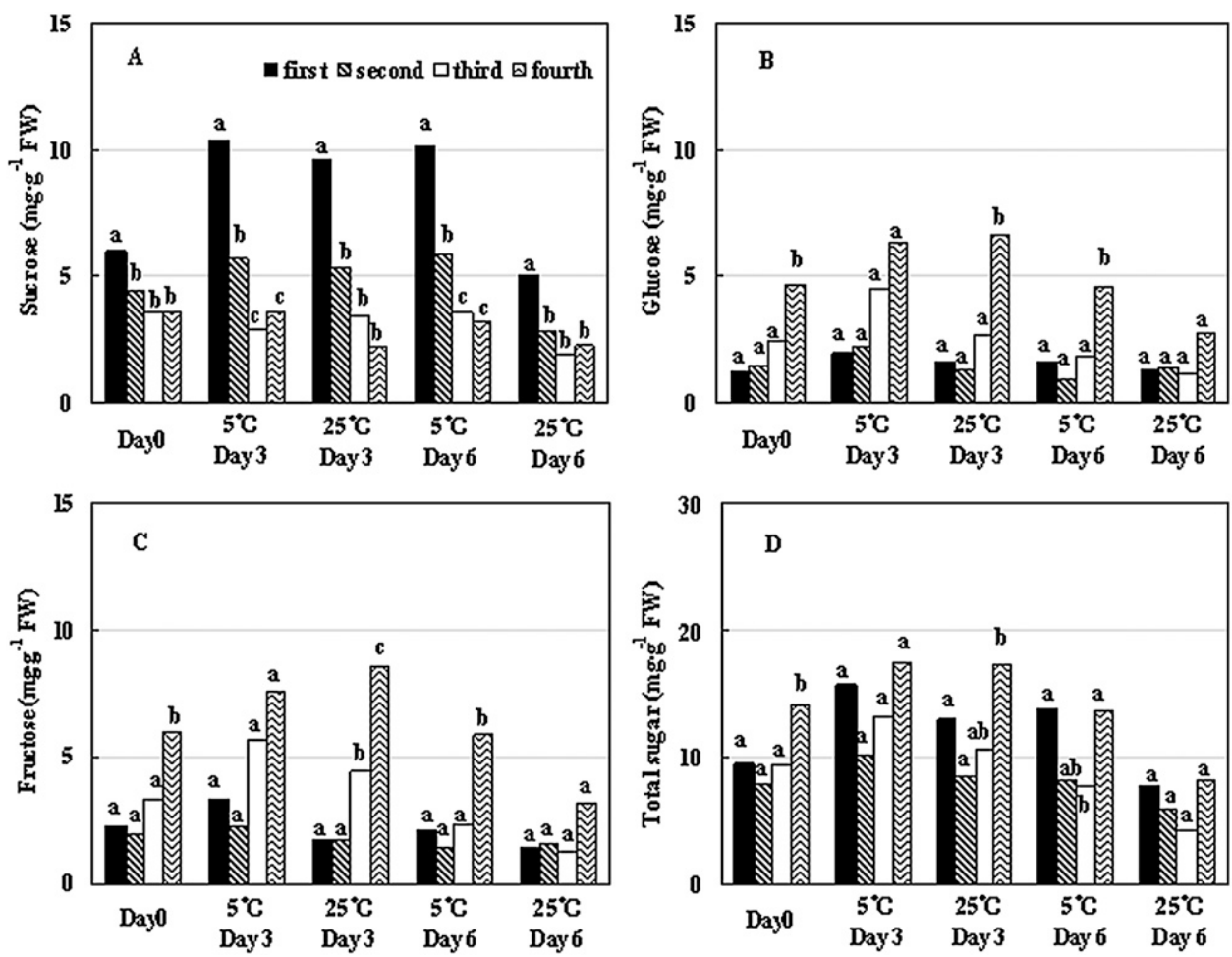

Fig. 4. Contents of sucrose (A), glucose (B), fructose (C), and total sugar (D) in different sections along the length of an emerged bamboo shoot harvested from Ohma area during storage at 5 and $25^{\circ} \mathrm{C}$. Each value is the mean of three replicates. Mean values with the same letter are not significantly different at the $5 \%$ level by Tukey's multiple range test.
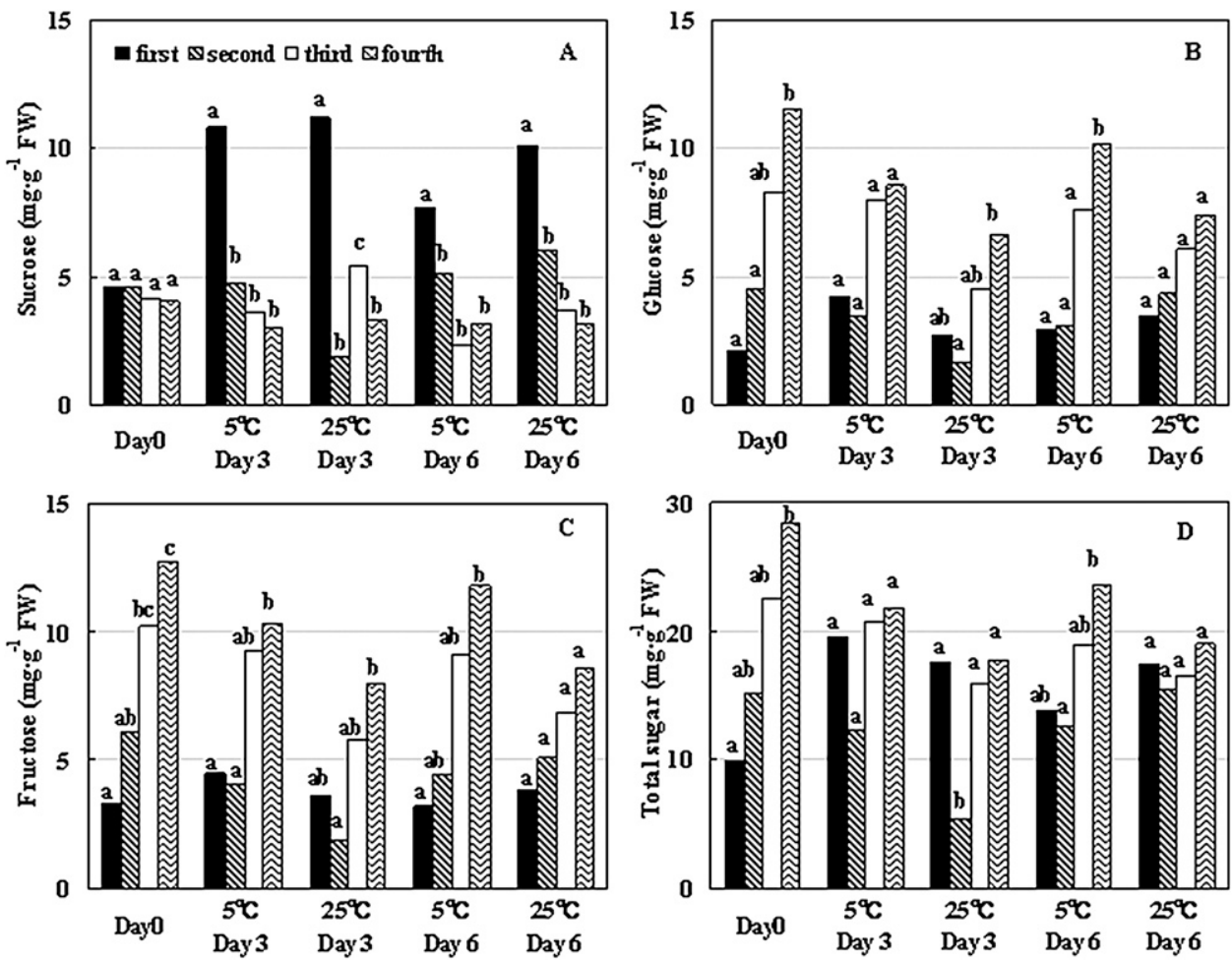

Fig. 5. Contents of sucrose (A), glucose (B), fructose (C), and total sugar (D) in different sections along the length of an underground bamboo shoot harvested from Ohma area during storage at 5 and $25^{\circ} \mathrm{C}$. Each value is the mean of three replicates. Mean values with the same letter are not significantly different at the $5 \%$ level by Tukey's multiple range test. 

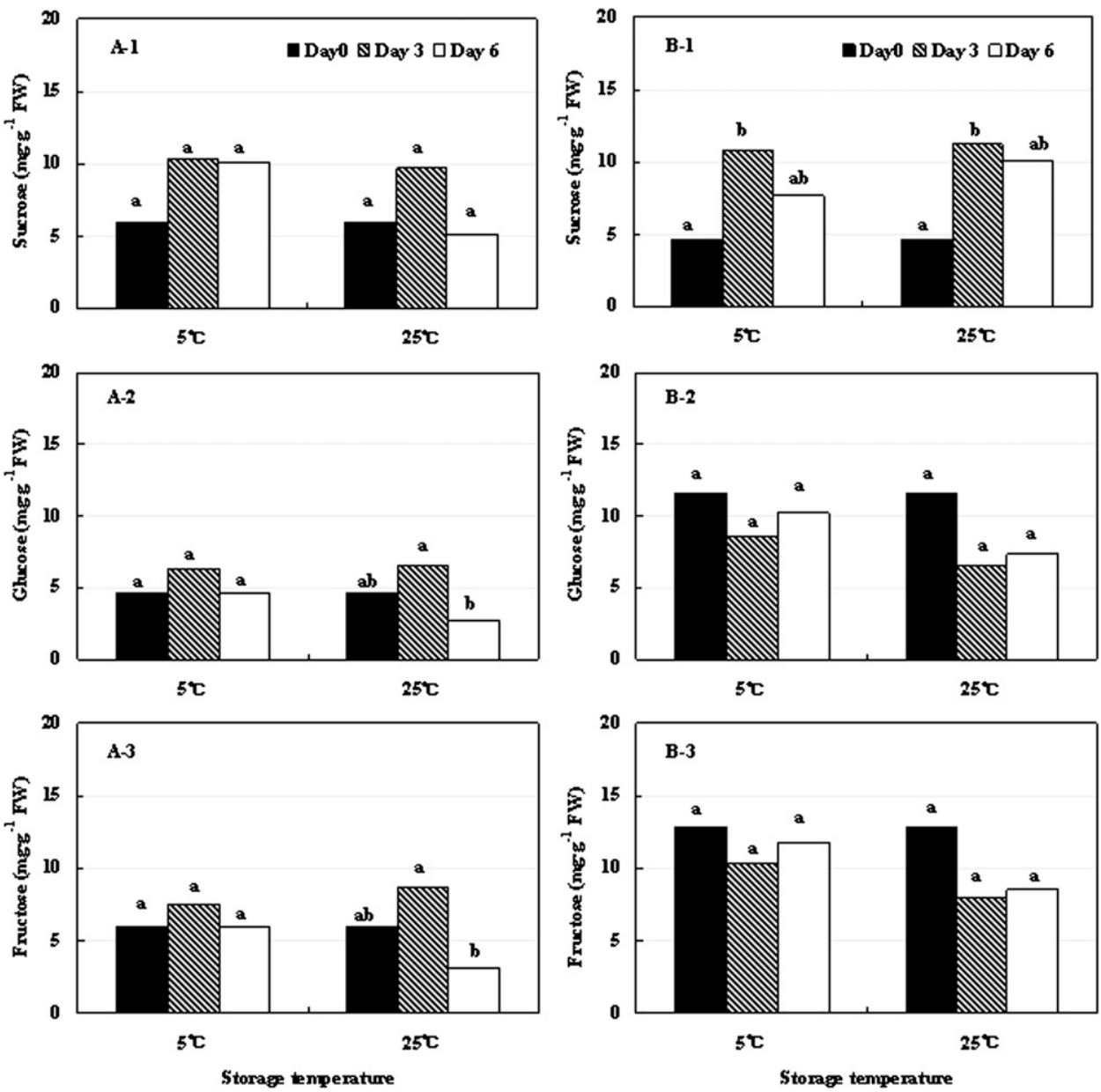

Fig. 6. Sugar contents of emerged (A) and underground (B) bamboo shoots harvested from Ohma area. Sucrose content (A-1, B-1) of the first section, and glucose content (A-2, B-2) and fructose content $(\mathbf{A}-\mathbf{3}, \mathbf{B}-\mathbf{3})$ of the fourth section of bamboo shoot during storage at 5 and $25^{\circ} \mathrm{C}$. Each value is the mean of three replicates. Mean values with the same letter are not significantly different at the $5 \%$ level by Tukey's multiple range test.

fructose and glucose in the basal section were twofold greater than that in the apical section. From our results, it is clear that there is a high degree of sucrose accumulation in the apical section, and glucose and fructose contents were highest in the basal section. These differences might be the result of the different physiological and biochemical properties among sections along the length of the shoot depending on each section's specific histology.

It has been suggested that the accumulated sugar enables elongation of the bamboo tissue, which appears to be induced by changes in the solute potential (Cosgrove, 1986; Hoffmann-Benning et al., 1997; Magel et al., 2005). Because photosynthetically active leaves do not develop before full culm expansion (Nath et al., 2004), the new bamboo culm hardly contributes by itself to biomass accumulation. In addition, during cell expansion, the culm itself is covered by a compacted layer of culm sheaths with barely any net rate of assimilation. Consequently, the growth and development of an expanding culm have to be supported by internal supplies of carbon that are distributed from storage tissues of the rhizome and storage tissues of the previous year's bamboo culm. Because the apical region of plants, including bamboo shoots, have high rates of cell division and expansion and thus greater sink strength, combined with the ability of a sink organ to attract sucrose. These might explain the greater accumulation of sucrose content in the apical section of bamboo shoots.

For the underground bamboo shoots, the changing pattern of sucrose content was similar to that of the emerged bamboo shoots. However, the highest contents of glucose, fructose, and total sugar were observed at Day 0 and then decreased at Days 3 and 6 (Figs. 5D and 6). Before a new bamboo culm is able to assimilate carbohydrates, its growth depends on the accumulated substance from older culms, which are either stored in the rhizome or transported directly from the older culms to the growing shoot (Liese, 1998). Our results also suggest that there were higher sugar contents in the underground bamboo shoots as compared with the emerged bamboo shoots. From this point of view, the accumulating mechanism of carbohydrates in bamboo shoots might be different between harvest maturity stages. In the immature underground bamboo shoots, surrounded by a soil environment, the transported carbohydrates might accumulate as sugars rather than as other forms, and they may be used directly as a major substance to support cellular metabolism during storage after harvest (Kays, 1991). Moreover, the results suggest that at Day 6 of storage, the sugar content of bamboo shoots stored at $25^{\circ} \mathrm{C}$ was lower than that of bamboo shoots stored at $5{ }^{\circ} \mathrm{C}$. It can be assumed that the lower storage temperature may slow the loss of sugar content in postharvest of bamboo shoots. Previous studies indicated that shelf life of bamboo shoots could be extended by reducing storage temperature and high-temperature conditions could enhance sugar use and respiration of the cell. Postharvest deterioration and changing in cellular components, including discoloration, browning, lignification, and increased PAL activity, were also observed in bamboo shoots stored at relatively high temperature (Chen et al., 1989; Matsui et al., 2004; Shen et al., 2006). On the other hand, a low temperature seems to slow cellular respiration and quality deterioration (Bron et al., 2005; Jones, 1942; Kattan and Pharr, 1971; Platenius, 1942; Saltveit, 2004; Zhang et al., 2002).

Storage of fruits and vegetables after harvest led to the changes of reducing sugars (fructose and glucose) and sucrose. Sucrose loss is accelerated by storage at room temperature ( 20 to $25^{\circ} \mathrm{C}$ ) and inhibited by lower temperature (Itai and Tanahashi, 2008; 
Lamikanra et al., 2000; Mao et al., 2006; Shono et al., 1997). A rapid loss of sucrose content was also observed in tips of harvested asparagus spear during storage at $20^{\circ} \mathrm{C}$ for 5 d (Irving and Hurst, 1993). However, from our results, the sucrose content in the first section of emerged and underground bamboo shoots increased significantly after $3 \mathrm{~d}$ of storage whether in 5 or $25^{\circ} \mathrm{C}$ (Figs. 4 , 5, and 6). So far, there are no referenced data on this changing characteristic in sucrose content of bamboo shoots. The detachment of a young bamboo shoot from a parent plant might inhibit use of sucrose and synthesis of cell wall polysaccharides, whereas there still might be support of translocated sucrose from lower portions to the top of the shoot. On the other hand, a high content of sucrose in the first section of a bamboo shoot might be the result of some recombination of reducing sugars (glucose and fructose) to sucrose during storage (Rutherford, 1981).

Overall, the changing characteristics of sugar content observed in this study reveal the specific accumulation patterns of individual sugars among four sections along the length of a bamboo shoot. Sucrose content was predominant in the tip section of bamboo shoots, whereas glucose and fructose content were high in the basal part. During storage, lowering temperature seemed to slow the loss of sugar contents, and sucrose of all bamboo shoots particularly seemed to increase after 3 $\mathrm{d}$ of storage. In addition, our results suggest that the maturity at harvest plays an important role in quality of fresh bamboo shoots according to the different patterns and contents of sugar accumulation observed between the emerged and underground bamboo shoots. Further study on the relationships between carbohydrate metabolism and cellular physiology in various bamboo shoots (cultivars, harvest maturity, soil conditions, cultivation areas, and so on) as well as the shelf life extension should be considered.

\section{Literature Cited}

Bron, I.U., D.C.C. Vitti, R.A. Kluge, M.C. Arruda, A.P. Jacomino, and G.P.P. Lima. 2005. Influence of low temperature storage and 1methylcyclopropene on the conservation of fresh-cut watercress. Braz. J. Food Technol. 8:121-126.

Chen, R.Y., M.S. Liu, T.C. Chang, and M.J. Tsai. 1989. Postharvest handling and storage of bamboo shoots (Bambusa oldhamii Munro). Acta Hort. 258:309-316.
Cosgrove, D.J. 1986. Biophysical control of plant cell growth. Annu. Rev. Plant Physiol. 37:377405.

Diver, S. 2001. Bamboo. A multi-purpose agroforestry crop. Current topic. Appropriate Technology Transfer for Rural Areas (ATTRA), Aug. 2001.

Fuchigami, M. 1990. Differences between bamboo shoots and vegetables in thermal disintegration of tissues and polysaccharides fractionated by successive extraction. J. Food Sci. 55:739745.

Hoffmann-Benning, S., L. Willmitzer, and J. Fisahn. 1997. Analysis of growth, composition and thickness of the cell walls of transgenic tobacco plants expressing a yeast-derived invertase. Protoplasma 200:146-153.

Irving, D.E. and P.L. Hurst. 1993. Respiration, soluble carbohydrates and enzymes of carbohydrate metabolism in tips of harvested asparagus spears. Plant Sci. 94:89-97.

Itai, A. and T. Tanahashi. 2008. Inhibition of sucrose loss during cold storage in Japanese pear (Pyrus pyrifolia Nakai) by 1-MCP. Postharvest Biol. Technol. 48:355-363.

Jones, W.W. 1942. Respiration and chemical changes of the papaya fruit in relation to temperature. Plant Physiol. 17:481-486.

Kader, A.A. 1996. Maturity, ripening, and quality relationships of fruit-vegetables. Acta Hort. 434:249-256.

Kattan, A.A. and D.M. Pharr. 1971. Effects of air flow rate, storage temperature, and harvest maturity on respiration and ripening of tomato fruits. Plant Physiol. 48:53-55.

Kays, S.J. 1991. Postharvest physiology of perishable plant products. An Avi Book. Van Nostrand Reinhold, New York, NY.

Kleinhenz, V., M. Gosbee, S. Elsmore, T.W. Lyall, K. Blackburn, K. Harrower, and D.J. Midmore. 2000. Storage methods for extending shelf life of fresh, edible bamboo shoots. [Bambusa oldhamii (Munro)]. Postharvest Biol. Technol. 19:253-264.

Kozukue, E. and N. Kozukue. 1981. Lipid content and fatty acid composition in bamboo shoots. J. Food Sci. 46:751-755.

Kozukue, E., N. Kozukue, and T. Kurosaki. 1983. Organic acid, sugar and amino acid composition of bamboo shoots. J. Food Sci. 48:935938.

Lamikanra, O., J.C. Chen, D. Banks, and P.A Hunter. 2000. Biochemical and microbial changes during the storage of minimally processed cantaloupe. J. Agr. Food Chem. 48:5955-5961.

Liese, W. 1987. Research on bamboo. Wood Sci. Technol. 21:189-209.

Liese, W. 1998. The anatomy of bamboo culms. Technical Report. INABR, Beijing, China.

Lu, S.M. and Y.G. Xu. 2004. Physiological and biochemical changes of fresh-cut bamboo shoot (Phyllostachys heterocycla var pubes- cens) during cold storage. J. Sci. Food Agr. 84:772-776.

Luo, Z., X. Xu, Z. Cai, and B. Yan. 2007. Effects of ethylene and 1-methylcyclopropene (1-MCP) on lignification of postharvest bamboo shoot. Food Chem. 105:521-527.

Magel, E., S. Kruse, G. Lütje, and W. Liese. 2005. Soluble carbohydrates and acid invertases involved in the rapid growth of developing culm in Sasa palmata (Bean) Camus. Bamboo Sci. Cult. 19:23-29.

Mao, L., F. Que, and G. Wang. 2006. Sugar metabolism and involvement of enzymes in sugarcane (Saccharum officinarum L.) stems during storage. Food Chem. 98:338-342.

Matsui, T., P.K. Bhowmik, and K. Yokozeki. 2004. Phenylalanine ammonia-lyase in Moso bamboo shoot: Molecular cloning and gene expression during storage. Asian J. Plant Sci. 3:315319.

Nath, A.J., G. Das, and A.K. Das. 2004. Phenology and culm growth of Bambusa cacharensis R. Majumdar in Barak Valley, Assam, North-East India. Bamboo Sci. Cult. 18:19-23.

Nirmala, C., E. David, and M.L. Sharma. 2007. Changes in nutrient components during ageing of emerging juvenile bamboo shoots. Intl. J. Food Sci. Nutr. 58:612-618.

Pharr, D.M. and H.N. Sox. 1984. Changes in carbohydrate and enzyme levels during the sink to source transition of leaves of Cucumis sativus L., a stachyose translocator. Plant Sci. Lett. 35:187-193.

Platenius, H. 1942. Effect of temperature on the respiration rate and the respiratory quotient of some vegetables. Plant Physiol. 17:179197.

Rutherford, P.P. 1981. Some biochemical changes in vegetables during storage. Ann. Appl. Biol. 98:538-541.

Saltveit, M.E. 2004. Respiratory metabolism. In: Gross, K.C., C.Y. Wang, and M. Saltveit (eds.). The commercial storage of fruits, vegetables, and florist and nursery stocks. USDA Agric. Handbook, No. 66. 24 Mar. 2009. <http://www. ba.ars.usda.gov/hb66/019respiration.pdf $>$.

Shen, Q., F. Kong, and Q. Wang. 2006. Effect of modified atmosphere packaging on the browning and lignification of bamboo shoots. J. Food Eng. 77:348-354.

Shono, Y., M. Yoshimura, S. Kimura, and N. Yamauchi. 1997. Sucrose metabolism in stored green peas. Food Sci. Technol. Intl. Tokyo 3:41-45.

Wang, Z., Q. Pan, and B. Quebedeaux. 1999. Carbon partitioning into sorbitol, sucrose, and starch in source and sink apple leaves as affected by elevated $\mathrm{CO}_{2}$. Environ. Exp. Bot. 41:39-46.

Zhang, M., Q. Tao, Y. Huan, H. Wang, and C. Li. 2002. Effect of temperature control and high humidity on the preservation of JUFENG grapes. Intl. Agrophys. 16:277-281. 